\title{
Divisão Sexual do Trabalho: a experiência de três mulheres em cargos de poder e de liderança
}

\author{
División Sexual del Trabajo: la experiencia de tres mujeres en cargos de \\ poder y de liderazgo
}
Sexual Division of Work: the experience of three women in positions of power and leadership

\author{
Paulla Hermann ${ }^{1}$ \\ Diênifer Kaus ${ }^{2}$
}

\begin{abstract}
Resumo
Com o objetivo de identificar nos discursos de mulheres que ocupam cargos de poder e de liderança vestígios da divisão sexual do trabalho, foram escolhidas três mulheres que ocupam cargos de maior patente nas instituições em que trabalham, sendo o estudo realizado com uma Delegada, uma Reitora e uma Oficial Superior das Forças Armadas. Esta divisão caracteriza-se pelo domínio público e produtivo por parte dos homens e pela conciliação das mulheres entre o domínio produtivo e reprodutivo. Também é identificada pela reprodução de estereótipos femininos e masculinos no mercado de trabalho. O que demonstra a dificuldade para o acesso de alguns cargos que apresentam maiores possibilidades de ascensão de carreira. Da análise efetuada argumenta-se pela necessidade da desconstrução dos estereótipos de liderança com relação aos gêneros para que se estabeleça igualdade nas condições e oportunidades.
\end{abstract}

Palavras-Chave: cargos de liderança; gênero; mulheres; poder.

\section{Resumen}

Con el objetivo de identificar en los discursos de mujeres que ocupan cargos de poder y de liderazgo vestigios de la división sexual del trabajo, fueron escogidas tres mujeres que ocupan cargos de mayor patente en las instituciones en que trabajan, siendo el estudio realizado con una Delegada, una Rectora y un Oficial Superior de las Fuerzas Armadas. Esta división se caracteriza por el dominio público y productivo por parte de los hombres y por la conciliación de las mujeres entre el dominio productivo y reproductivo. También es identificada por la reproducción de estereotipos femeninos y masculinos en el mercado de trabajo. Lo que demuestra la dificultad para el acceso de algunos cargos que presentan mayores posibilidades de ascenso de carrera. Del análisis efectuado se argumenta por la necesidad de la deconstrucción de los estereotipos de liderazgo con relación a los géneros para que se establezca igualdad en las condiciones y oportunidades.

Palabras claves: cargos de liderazgo; género; mujeres; poder.

\begin{abstract}
With the objective of identifying in the discourses of women who hold positions of power and leadership traces of the sexual division of work, three women were chosen to hold higher positions in the institutions in which they work. The study was conducted with a Delegate, a Rector and a Senior Armed Forces Officer. This division is characterized by the public and productive domain by the men and the conciliation of the women between the productive and reproductive domain. It is also identified by the reproduction of female and male stereotypes in the labor market. This demonstrates the difficulty of accessing some positions that present greater possibilities

\footnotetext{
${ }^{1}$ Graduanda em Psicologia; Universidade Federal do Rio Grande (FURG); Rio Grande, Rio Grande do Sul, Brasil; paulla.hdoamaral@gmail.com

${ }^{2}$ Graduanda em Psicologia; Universidade Federal do Rio Grande (FURG); Rio Grande, Rio Grande do Sul, Brasil; dieniferkaus@gmail.com
} 
for career advancement. From the analysis made, one argues for the need to deconstruct gender stereotypes of leadership in order to establish equality in conditions and opportunities.

Keywords: gender; leadership positions; power; women.

\section{Introdução}

Na sociedade atual ainda há uma nítida divisão entre o domínio público e produtivo, pertencido pelos homens que ocupam um papel de provedor da família e o privado e reprodutivo, pertencido pelas mulheres que são designadas como donas do lar em contrapartida do sustento financeiro do marido. Entretanto, quando a mulher entra no mundo produtivo ela não se afasta das responsabilidades do mundo privado. Cria-se então, o modelo tradicional e o modelo de conciliação. No modelo tradicional, a mulher tem papel na família e papel domésticos inteiramente assumidos por ela, enquanto o papel de provedor é atribuído aos homens. E no modelo de conciliação, cabe à mulher conciliar a vida familiar com a vida profissional. Através desta configuração, a divisão sexual do trabalho é reconfigurada baseando-se na dicotomia público/privado que está associada ao trabalho remunerado/não remunerado. O que estabelece uma relação assimétrica entre os sexos, cria e reproduz concomitantemente as desigualdades de papéis e funções na sociedade (SOUSA; GUEDES, 2016; HIRATA; KERGOAT, 2007).

A divisão sexual do trabalho auxilia na manutenção do vínculo entre trabalho remunerado e não remunerado. $\mathrm{O}$ ingresso das mulheres no mundo produtivo não equilibra as funções atribuídas aos sexos, ao contrário, reforça as desvantagens vividas por elas, pois assumem praticamente sozinhas as atividades do espaço privado. Assim, é possível observar que as obrigações domésticas limitam o desenvolvimento profissional das mulheres, o que pode acarretar em carreiras descontínuas, salários mais baixos e empregos de menor qualidade (BRUSCHINI, 2006 apud SOUSA; GUEDES, 2016).

Ao contrário de reflexões que enxergam o mundo do trabalho como completamente guiado pela busca da maximização do lucro, sabe-se que o trabalho também é uma esfera da vida social permeada por classificações e expectativas sociais que impactam a vida das trabalhadoras e trabalhadores. Dentre eles está o princípio de gênero, em que as tarefas existentes no mercado de trabalho são divididas entre os indivíduos baseando-se na diferença sexual. Nesta perspectiva, homens e mulheres assumem diferentes atividades sob a justificativa de serem biologicamente mais adequados para determinadas tarefas e não outras. Portanto, a natureza dos corpos justificaria os "trabalhos femininos" e "trabalhos masculinos" (DANIEL, 2011). 
A construção social do trabalho estereotipado em feminino e masculino marcam as atividades dos homens que são associados ao trabalho pesado, penoso, sujo e insalubre, e das mulheres que são associadas com a feminilidade, o trabalho leve, fácil, limpo e que exige paciência, cuidado e altruísmo. Essa forma de divisão social do trabalho tem dois princípios organizadores: o princípio de separação que é dividido entre trabalho de homens e trabalho de mulheres e o princípio hierárquico em que um trabalho de homem "vale" mais que o de uma mulher. Estas divisões rebaixam o gênero ao sexo biológico e reduzem as práticas sociais a "papéis sociais" sexuados (SOUSA; GUEDES, 2016; HIRATA; KERGOAT, 2007).

A divisão entre masculino e feminino sofre modificações à medida que as mulheres passam a ocupar mais cargos ditos masculinos no mercado de trabalho. Este ingresso justifica-se através dos avanços tecnológicos e culturais como o desenvolvimento de métodos contraceptivos, o direito ao voto, as novas configurações familiares e a busca pela qualificação. Tais aspectos culminaram na impulsão e especialização das mulheres no mercado de trabalho, levando-as a conquistar um maior espaço e a ocupar cada vez mais as lideranças das grandes empresas (BAYLÃO; SCHETTINO, 2014).

Em relação a cargos de chefia, estes ainda são ocupados na maioria das vezes por homens, que perfazem $78,6 \%$, enquanto as mulheres representam apenas $21,4 \%$. Estes dados demonstram a dificuldade para o acesso de alguns cargos que apresentam maiores possibilidades de ascensão na carreira, restando apenas ocupações e salários inferiores para as mulheres (MINISTÉRIO DO TRABALHO, 2009; CAPELLE et al, 2004 apud OLIVEIRA; GAIO; BONACIM, 2009).

O tratamento desigual nas relações de trabalho pode ser representado em duas formas de segregação, a vertical e a horizontal. O afastamento das mulheres dos cargos de liderança mantendo-as em cargos de subordinação, representa a segregação vertical. A diferença salarial e ocupacional e a separação de atividades em femininas e masculinas que resultam em escolhas baseadas em questões de gênero, representam a segregação horizontal (OLINTO, 2011).

O campo de trabalho pode ser um reflexo do modelo patriarcal em que as mulheres estão submetidas, reforçando estereótipos femininos negativos. Tais como a menor disposição para viagem, o que é desmentido pelo número expressivo de aeromoças e menores condições para enfrentar perigo físico e força física inferior, que poderá afastar as mulheres das funções de bombeiro, policial, vigilante, quando hoje há muitas exercendo essas ocupações (BARROS, 2008). 


\section{Metodologia}

Tendo presente os estudos acerca da divisão sexual do trabalho, desenvolveu-se uma pesquisa de natureza qualitativa com mulheres que ocupam importantes cargos de poder e de liderança na região Sul do Rio Grande do Sul. Utilizou-se o método de amostragem por julgamento, que proporciona uma amostra de pessoas que detêm um maior conhecimento sobre a temática.

Com o objetivo de identificar nos discursos de mulheres que ocupam cargos de poder e de liderança vestígios da divisão sexual do trabalho, foram escolhidas três mulheres que ocupam cargos de maior patente nas instituições em que trabalham, sendo o estudo realizado com uma Delegada, uma Reitora e uma Oficial Superior das Forças Armadas. Cabe destacar que as entrevistadas foram as primeiras em sua ocupação na história das suas instituições. Elegeu-se apenas três mulheres, considerando-se a variabilidade discursiva e não com o tamanho da amostra. A inclusão definitiva das mulheres ocorreu somente após a concordância das participantes expressa através da assinatura do Termo de Consentimento Livre e Esclarecido (TCLE).

As entrevistas semiestruturadas foram realizadas e gravadas nos ambientes de trabalho, logo em seguida foram transcritas e submetidas à análise. As entrevistas realizadas durante os meses de outubro e novembro de 2017, com duração média de uma hora, foram divididas em dados de identificação e questões relacionadas com a temática, entre elas o histórico profissional dessas mulheres, como suas formações, motivações e obstáculos enfrentados; a visão das entrevistadas sobre os cargos que ocupam e sobre seus ambientes de trabalho; a visão sobre a inserção das mulheres no mercado de trabalho, bem como a visão sobre cargos de liderança ocupados por mulheres.

\section{Resultados e discussão}

As mulheres em cargos de liderança ocupam posições de poder, o que as torna vítimas dos discursos que são obrigadas a produzir. Discursos estes que, muitas vezes, reforçam o estereótipo de gênero nas organizações. Desta forma, os papéis de liderança exercidos por essas mulheres são perpetuados, influenciando outros membros da instituição. Cabe destacar que a liderança é uma competência pautada nas relações entre duas ou mais pessoas e que está baseada no exercício de influência. É neste exercício de liderança que se exerce o poder. Para Foucault, o poder pode se instituir, tanto pelos discursos a que lhe é obrigada a produzir, quanto pelos movimentos dos quais os indivíduos tornam-se vitimados pela própria 
organização que a acomete e, por vezes, sem a devida consciência e reflexão (FERREIRINHA; RAITZ, 2010).

Nesta perspectiva, o líder passa a ocupar uma posição adequada para apresentar alternativas culturais a serem adotadas em um determinado grupo. Na medida que isto se faz presente no ambiente profissional, é possível compreender a articulação entre poder, cultura e liderança e como as diversas culturas existentes podem influenciar os membros de uma organização

(MERHI et $a l$, 2010).

Sobre a discussão da divisão do mundo público e produtivo e do mundo privado e reprodutivo observou-se um grande incômodo que as mulheres relataram haver elevada cobrança de seus superiores para que elas obtivessem êxito no trabalho e de seus familiares para com tarefas domésticas, exercendo um modelo de conciliação.

As responsabilidades da mulher no mundo privado continuam sendo pertinentes mesmo após sua entrada no mercado de trabalho, incumbindo-a a conciliar a vida familiar com a vida profissional, como mencionado no seguinte trecho: “....E infelizmente ainda temos chefes que pensam "pra que que vocês foram inventar de sair pra trabalhar? Então agora deem conta de tudo!" eu já escutei isso e foi recentemente." A cobrança dos familiares e a falta de apoio quando a mulher decide fazer parte do mundo público e produtivo é reforçada na seguinte fala: "Então não é fácil, mesmo esse apoio é um apoio sempre de cobrança, porque o papel da mulher na família a gente é sempre muito cobrada. A presença do marido na família não é cobrada mas a ausência da mulher é!”

Em relação a construção de cargos ditos femininos e masculinos, duas das três mulheres confirmaram o estereótipo negativo em seus discursos. Afirmando a necessidade de ter que assumir características ditas masculinas para poder exercer uma boa liderança. A reprodução desse comportamento por homens e mulheres perpetuam sistemas desiguais, os quais privilegiam os homens.

Esses privilégios podem passar despercebidos criando falsas impressões de ambientes meritocráticos, como relatou uma das entrevistadas: "Eu brinco que eu acho que eu tenho um pouco mais de hormônios masculinos do que femininos, porque eu penso um pouco como homem, no sentido de ser objetiva."

Os discursos revelam o princípio de separação quando se observa que cargos de liderança são reconhecidos como cargos masculinos exercido através de características masculinas. Enquanto isso, mulheres líderes, por possuírem uma postura com estereótipos femininos acabam sendo prejudicadas. Estas crenças estereotipadas, impostas as mulheres, são desvalorizadas e atribuídas a um caráter negativo, o que reforça a supremacia masculina, 
como mencionado no trecho a seguir: "As vantagens são por ser mulher, eu acho que a mulher em um cargo de liderança ela tem uma diferença, nós temos uma diferença na forma como a gente lida com os problemas. E a desvantagem é nossa própria emoção e sensibilidade que é da mulher né, e que às vezes a gente sofre muito, mais do que talvez o homem sofreria".

As entrevistadas confirmam o princípio hierárquico quando apontam a necessidade de haver um maior esforço e dedicação em seu trabalho para que sejam reconhecidas da mesma maneira que os homens.

A mulher que se liberta economicamente do homem nem por isso alcança uma situação moral, social e psicológica idêntica à dele. A maneira por que se empenha em sua profissão e a ela se dedica depende do contexto constituído pela forma global de sua vida (ÁLVARES, 2014). O que pode ser observado na seguinte fala: "Eu sei que eu tive que nesse período trabalhar muito mais do que um homem. Porque eu tive que me superar muito, eu tive que trabalhar muito também! Talvez em alguns aspectos, não para mostrar [...] que eu sabia, mas para mim mesma. Para eu me sentir mais segura, porque como mulher, ocupar um cargo deste que na maior parte é ocupado por homens... Mas sempre que eu tinha que tomar uma decisão eu tinha que me fundamentar muito mais, eu imagino do que se eu fosse um homem!"

Com relação ao mercado de trabalho observou-se uma confirmação, nos discursos das mulheres, da presença da segregação vertical e horizontal. O que pode dificultar o acesso a ocupações que permitem um avanço na carreira, observado na fala de uma das entrevistadas: “...as mulheres ainda ganham menos do que os homens. E se tem muito mais trabalho pra se conquistar atualmente até pela quantidade, o número de mulheres é bem menor do que o de homens no mercado de trabalho. Dependendo da profissão menos ainda." O seguinte trecho reforça a dificuldade para ocupar cargos de liderança no mercado de trabalho: " $E$ a gente sabe que no mundo que a gente tá vivendo hoje há um retrocesso em conquistas então tem espaço mas pra ocupar esse espaço não é fácil."

\section{Conclusões}

Pode-se identificar nos discursos das três entrevistadas que a divisão sexual do trabalho está presente cotidianamente na vida pessoal e profissional destas mulheres. Tornando-se prejudicial e criando obstáculos para que elas se mantenham, de forma satisfatória, em suas posições de liderança. Tendo que, muitas vezes, incorporar estereótipos masculinos para que consigam ser respeitadas em seu ambiente de trabalho. 
Apesar das obrigações domésticas, muitas vezes, limitarem o desenvolvimento profissional das mulheres, as entrevistas confirmam que através dos avanços houve maior conquista de um espaço e a impulsão e especialização no mercado de trabalho. Por outro lado, a estrutura social não foi profundamente modificada pela evolução da condição feminina. Este mundo, que sempre pertenceu aos homens, conserva ainda a forma que eles lhe imprimiram.

Os estereótipos femininos e masculinos são constituídos através das relações de poder estabelecidas na sociedade e que se perpetuam no mercado de trabalho. Esses estereótipos de gênero condicionam o corpo feminino a um tipo específico de papel social, de personalidade, de profissões e de ocupação no espaço público.

A divisão sexual do trabalho reforça a desigualdade de papéis e funções na sociedade. Confirmando que para que haja igualdade, torna-se necessário ser igual ao que detém o poder. Como alternativa, é necessário que haja uma desconstrução dos estereótipos de liderança com relação aos gêneros para que se estabeleça igualdade nas condições e oportunidades.

\section{Referências}

ÁLVARES, M. L. M. Beauvoir, o patriarcado e os mitos nas relações de poder entre homens e mulheres. Revista do NUFEN: phenomenology and interdiciplinary, v. 6, n. 01, p. 6-14, 2014. ISSN 2175-2591. Disponível em: http://pepsic.bvsalud.org/pdf/rnufen/v6n1/a02.pdf. Acesso em: 12 dez. 2018.

BARROS, A. M. Cidadania, relações de gênero e relações de trabalho. Revista Tribunal Regional do Trabalho $3 a$ Região, v. 47, n. 77, p. 67-83, jan./jun. 2008. ISSN 0076-8855. Disponível em: https://www.trt3.jus.br/escola/download/revista/rev_77/Alice_Barros.pdf. Acesso em: 20 out. 2018.

BAYLÃO, A. L. S. B.; SCHETTINO, E. M. O. A inserção da mulher no mercado de trabalho brasileiro. In: XI SIMPÓSIO DE EXCELÊNCIA EM GESTÃO E TECNOLOGIA, 2014, Rio de Janeiro. Anais XI Simpósio de Excelência em Gestão e Tecnologia, Rio de Janeiro, 2014.

DANIEL, C. O trabalho e a questão de gênero: a participação de mulheres na dinâmica do trabalho. O Social em Questão, n. 25/26, p. 323-344, 2011. ISSN 2238-9091. Disponível em: http://osocialemquestao.ser.puc-rio.br/media/17_OSQ_25_26_Daniel.pdf. Acesso em: 12 dez. 2018.

FERREIRINHA, I. M. N.; RAITZ, T. R. As relações de poder em Michel Foucault: reflexões teóricas. Revista de Administração Pública, v. 44, n. 2, p. 367-383, mar./ abr. 2010. ISSN 0034-7612. Disponível em: http://www.scielo.br/scielo.php?pid=S0034$76122010000200008 \&$ script=sci_abstract\&tlng=pt. Acesso em: 21 out. 2018.

HIRATA, H.; KERGOAT, D. Novas configurações da divisão sexual do trabalho. Cadernos de Pesquisa, v. 37, n. 132, p. 595-609, set./dez. 2007. ISSN 1980-5314. Disponível em: http://www.scielo.br/scielo.php?script=sci_arttext\&pid=S0100-

15742007000300005\&lang=pt. Acesso em: 25 out. 2018. 
MERHI, D; VASCONCELOS, K. A.; LOPES, V. M. G.; SILVA, A. R. L. Cultura, Poder e Liderança nas Organizações: um Estudo de Caso no Setor de Celulose. Revista Eletrônica de Administração, v. 16, n. 3, p. 737-765, set./dez. 2010. ISSN 1413-2311. Disponível em: www.redalyc.org/pdf/4011/401137517010.pdf. Acesso em: 20 out. 2018.

OLINTO, G. A inclusão das mulheres nas carreiras de ciência e tecnologia no Brasil. Inclusão Social, v. 5, n. 1, p. 68-77, 2011. ISSN 1518-8353. Disponível em: http://revista.ibict.br/inclusao/article/view/1667. Acesso em: 25 out. 2018.

OLIVEIRA, A. R.; GAIO, L. E.; BONACIM, C. A. G. Relações de gênero e ascensão feminina no ambiente organizacional: um ensaio teórico. Revista de Administração da UFSM, v.2, n.1, p. 80-97, jan./abr. 2009. ISSN 1983-4659. Disponível em: https://periodicos.ufsm.br/reaufsm/article/view/1279. Acesso em: 21 out. 2018.

SOUSA, L. P.; GUEDES, D. R. A desigual divisão sexual do trabalho: um olhar sobre a última década. Estudos avançados, v. 30, n. 87, p. 123-139, maio/ago. 2016. ISSN 18069592. Disponível em: http://www.scielo.br/scielo.php?script=sci_arttext\&pid=S010340142016000200123. Acesso em: 20 out. 2018. 